\title{
Recruiting older patients with peripheral arterial disease: evaluating challenges and strategies
}

\author{
This article was published in the following Dove Press journal: \\ Patient Preference and Adherence \\ 6 August 2015 \\ Number of times this article has been viewed
}

\author{
Diana P Brostow \\ Alan T Hirsch ${ }^{2}$ \\ Mindy S Kurzer ${ }^{3,4}$ \\ 'Veterans Affairs Eastern Colorado \\ Health Care System, Denver, CO, \\ USA; ${ }^{2}$ Department of Medicine, \\ Vascular Medicine Program, University \\ of Minnesota, Twin Cities, Minneapolis, \\ MN, USA; ${ }^{3}$ Department of Food \\ Science and Nutrition, University of \\ Minnesota, Twin Cities, ${ }^{4}$ Healthy Lives \\ Institute, St Paul, MN, USA
}

Correspondence: Diana P Brostow Veterans Affairs Eastern Colorado Health Care System, 1055 Claremont Street, Research AI5I, Denver, CO 80220, USA Email brostow.d@gmail.com

\begin{abstract}
Peripheral arterial disease (PAD) is a group of syndromes characterized by chronic and progressive atherosclerosis with a high burden of physical disability and cardiovascular morbidity and mortality. Recruiting patients for clinical research is therefore challenging. In this article, we describe and evaluate our methods for recruiting participants for a cross-sectional feasibility study of PAD, nutritional status, and body composition. We used convenience and purposive sampling approaches to identify potential participants. Between May 2012 and April 2013, 1,446 patients were identified, and 165 patients (11.4\%) responded to recruitment requests. The final enrollment was 64 participants $(64 / 1,446 ; 4.4 \%)$, and four subjects $(6.3 \%)$ subsequently withdrew from the study. Recruiting PAD patients presents a variety of challenges, due largely to the burdens of living with coexistent illnesses, and patients' reluctance or inability to travel for research. In this article, we delineate suggestions for improving the efficacy of recruitment methods in future PAD studies.
\end{abstract}

Keywords: community-based programs, depression, ethnicity, geriatrics, progressive illness and disease, mental health and illness, minorities

\section{Introduction}

Peripheral arterial disease (PAD), also known as peripheral vascular disease, comprises a range of vascular syndromes. Characterized by arteriosclerosis in vasculature other than the heart or brain, the term most commonly refers to atherosclerotic disease in the infrarenal aorta and the lower extremities. ${ }^{1}$ PAD is the most common cause of limb amputation, and regardless of localization or type of stenosis, all PAD syndromes are associated with a significant risk of cardiovascular events, including infarction and stroke. ${ }^{2}$ PAD patients are also at a significantly increased risk of cardiovascular disease (CVD)-related mortality, with rates exceeding those for CVD alone. ${ }^{3}$

At any point, up to $14 \%$ of Americans have PAD, and it is estimated that there are over 10 million sufferers in all of North America. ${ }^{4}$ Accurate data are difficult to collect, however, as half to two-thirds of affected people are asymptomatic prior to an ischemic event, ${ }^{5}$ and prevalence estimates do not account for people whose clinical measures fall on the cusp of official diagnosis. Established risk factors for PAD include smoking, diabetes mellitus, dyslipidemia, hypertension, obesity, and a family history of CVD or PAD. ${ }^{6}$ As a result, patients experience a high frequency of comorbid conditions that can exacerbate atherosclerotic progression. The health cost burden of PAD is also significant. Over 21 billion dollars are spent annually on treatment in the United States, which surpasses CVD treatment expenditures by up to $23 \%$. $^{3,7}$ 


\section{Treatment approaches}

Clinical guidelines for PAD treatment center around two concerns: improving patients' quality of life and decreasing the risk of incident CVD events. Exercise therapy is an established treatment approach, particularly if medically supervised and centered around improving ambulation and pain-free walking distance. ${ }^{1,8}$ Nevertheless, clinicians often initiate treatment solely with pharmacological interventions, and these focus on mitigating the pain and impaired walking ability that are hallmarks of PAD and on modifying risk factors that contribute to ischemic risk. Additionally, depending on a patient's age, vascular anatomy, and comorbid conditions, clinicians will employ revascularization procedures to restore blood flow in affected arteries. Nevertheless, PAD is a progressive illness, and the benefits of revascularization are generally not durable, regardless of treatment type. ${ }^{9}$ Additionally, revascularization procedures frequently result in complications that require repeated intervention and further contribute to disease and health cost burdens. ${ }^{10}$ A recent clinicians' conference reported that PAD is generally underdiagnosed and undertreated and that an emphasis on late-stage treatment has created gaps in research relative to other vascular diseases. ${ }^{3}$ Consequently, there is an emerging body of research in lifestyle-based therapies for preventing or treating PAD, particularly exercise, ${ }^{11}$ and to a smaller degree nutrition. ${ }^{12}$

\section{Obstacles to research}

Nutrition research in PAD has been sparse, and studies have largely relied on subpopulations of epidemiological cohorts. These studies reported generalized observations of eating habits and dietary patterns and broadly delineated some nutrients of interest. More specific investigations of patients' nutritional status, however, have come across significant challenges. Sample sizes are small, ranging from $16^{13}$ to $232^{14}$ in cross-sectional, prospective, and randomized trial studies alike. PAD patients tend to be older, have multiple comorbidities, and have diminished physical mobility, all of which create a population that is difficult to recruit and retain.

Small sample sizes limit the validity of nutrition studies in PAD research. Internal biases, such as convenience sampling and self-selection bias by healthier patients hinder the generalizability of study results to a wider population. The inability to recruit sufficiently large cohorts also has implications for clinical practice. Small sample sizes limit the ability to detect potentially significant associations and outcomes, calling into question whether taking advantage of patients' time and investigators' resources is useful or ethical. Describing obstacles to recruitment and retention is an important step in expanding the body of research on nutrition and PAD and is crucial to developing evidencebased recommendations for clinical practice. In this article, we evaluate the experiences and obstacles encountered while recruiting patients for a cross-sectional study of nutritional status, body composition, and PAD severity.

\section{Methods}

Recruitment and data collection took place simultaneously and lasted 12 months, from May 2012 to April 2013. Initially, all identified patients were considered eligible for recruitment regardless of revascularization status; however, patients were excluded if they had undergone revascularization procedures within the previous 6 months. In an effort to delineate more precisely the associations between nutrition, body composition, and PAD severity, recruitment criteria were modified at the 6-month mark to prioritize patients with native vasculature. Exclusion criteria included unconfirmable PAD diagnosis, lack of English literacy, lack of transportation, as well as any patients who were double-leg amputees, were wheelchair-bound, or had diminished ability to provide informed consent due to dementia, Alzheimer's disease, or other cognitive limitations.

A university-affiliated health care organization conducted a database search of all patients who had PAD-related billing entries, at any time, in the greater Minneapolis/St Paul area. PAD-related billing entries comprised codes for pharmacological treatment of peripheral vasculature, peripheral revascularization procedures, and related diagnostic procedures and specialist referrals. In accordance with health care organization protocols, study coordinators were not given access to patients identified in this manner, and patient names with mailing addresses were given to a third-party service for compiling and shipping recruitment packets. The recruitment packet consisted of contact information, a summary of the study, an offer of modest financial reimbursement upon completion of data collection, transportation directions, and a consent form. When a packet recipient contacted the study coordinator, the potential subject was asked first verbally to confirm that he/she had a PAD diagnosis and second be able to verbalize whether he/she had undergone a revascularization procedure, and when. Patients who could not answer both questions were deemed ineligible, even if the person expressed confidence about a PAD diagnosis.

Additionally, vascular clinicians from three area hospitals personally screened and referred PAD patients to the study. Clinicians provided information to patients they deemed eligible candidates for participation, and with a patient's consent, 
his/her contact information was provided to the study coordinator. Patients referred by clinicians and who met all inclusion criteria were invited to participate via telephone, and the study coordinator verbally presented recruitment material. Patients who expressed interest were then asked for a mailing address and mailed transportation directions and a consent form.

Each potential subject completed the consent process in person at the research clinic and was asked to complete one clinic visit, along with two telephone dietary interviews. Participants were asked to fast for a minimum of 8 hours prior to their clinic visits and were offered a full breakfast immediately after completing a blood draw. As compensation for their time, participants were given modest financial reimbursement after the clinic visit and again after completing both telephone dietary interviews. Consent forms stipulated that if blood tests indicated any abnormality (eg, vitamin D deficiency), patients would be notified and given information to convey to their physicians. The study protocol and study-related documents were approved by the University of Minnesota Institutional Review Board.

\section{Results}

Of the 1,374 PAD patients identified through billing records and mailed recruitment packets, $93(6.8 \%)$ contacted the study coordinator, $30(2.2 \%)$ consented to participation, and $26(1.9 \%)$ actively participated in data collection. All 72 patients directly referred by clinicians were telephoned at least twice to attempt to establish contact and attempt recruitment. Of those, 34 (22.3\%) consented to and participated in the study. In all, of the 1,446 potential participants, recruitment was attempted with a total of 165 patients $(11.4 \%)$. Patients' age, sex, race/ethnicity, and revascularization status did not differ by recruitment method. Of the 165 potential subjects, 60 patients (4.1\%) ultimately participated, and of the remaining 105, 39 (23.6\%) outright declined to participate. All reasons for nonparticipation are presented in Table 1. Most frequent reasons were either an inability to maintain contact with patients to proceed with obtaining consent and scheduling or difficulty with transportation to the research site. An additional 28 (17\%) patients could not be contacted at all, and 34 (20.6\%) patients were considered ineligible.

Of the four participants who consented to but did not complete data collection, follow-up telephone calls revealed that two participants had difficulty with driving to or finding the clinic, and two declined to give a reason. Of the 60 official participants, 25 (41.7\%) completed the clinic visit and both telephone interviews. Two patients completed only one additional telephone interview, and 33 (55\%) solely attended
Table I Reasons for nonparticipation

\begin{tabular}{|c|c|c|}
\hline Classification $(n=77)$ & Reason detail & $\mathbf{n}$ \\
\hline \multirow[t]{2}{*}{$\begin{array}{l}\text { Expressed interest } \\
(n=23)\end{array}$} & $\begin{array}{l}\text { Could not be reached after } \\
\text { initial contact }\end{array}$ & 19 \\
\hline & $\begin{array}{l}\text { Consented, but dropped } \\
\text { out prior to data collection }\end{array}$ & 4 \\
\hline \multirow[t]{3}{*}{$\begin{array}{l}\text { Not interested } \\
(n=20)\end{array}$} & $\begin{array}{l}\text { Unable or unwilling to } \\
\text { procure transportation }\end{array}$ & II \\
\hline & Too busy, work responsibilities & 2 \\
\hline & No reason given & 7 \\
\hline \multirow[t]{8}{*}{ Ineligible $(n=34)$} & History of revascularization(s) & 14 \\
\hline & Unconfirmable PAD diagnosis & II \\
\hline & Double-leg amputee & 3 \\
\hline & Dementia/Alzheimer's disease & 2 \\
\hline & Wheelchair-bound & $\mathrm{I}$ \\
\hline & Recent bodily injury & I \\
\hline & Lack of English proficiency & I \\
\hline & $\begin{array}{l}\text { Deceased between initial } \\
\text { contact and follow-up }\end{array}$ & I \\
\hline
\end{tabular}

Abbreviation: PAD, peripheral arterial disease.

the clinic portion of the study. Upon finishing their clinic visits, three of the 35 noncompletes declined to take part in telephone interviews, but gave no reason for doing so. The remaining 32 participants were considered noncompletes as they could not be reached after repeated follow-up attempts. There were no significant differences (clinical or otherwise) between patients who completed the study, partially completed, or dropped out. Selected participants' characteristics are presented in Table 2. Although male participants outnumbered females 2:1 (PAD incidence in general does not differ by $\operatorname{sex}^{1}$ ), patients did not differ significantly by sex, age, race/ ethnicity, or any other demographic variable.

\section{Discussion Recruitment methods, strengths, and limitations}

This study underscores the difficulties inherent in recruiting PAD patients for a study of nutrition and body composition. While the sample size of 60 falls well within the range of cohort sizes in other PAD studies, ${ }^{13,14}$ it is a small size from which to extrapolate generalizable reasons for nonparticipation. Furthermore, the necessity of maintaining patients' privacy when identified via health care billing entries precluded obtaining information about patients who had no interest in research participation. As a result, we were unable to assess, when recruited through purposive sampling, if and how nonparticipants may fundamentally differ from participants.

Convenience sampling was the most effective recruitment method and yielded the majority of participants. It is the predominant method of recruiting subjects in other studies of PAD 
Table 2 Selected characteristics of the PAD study cohort, by revascularization status

\begin{tabular}{|c|c|c|c|c|c|c|c|}
\hline & Total $(n=60)$ & $\%$ & $N V(n=25)$ & $\%$ & $\operatorname{RV}(n=35)$ & $\%$ & $P$-value \\
\hline \multicolumn{8}{|l|}{ Sex } \\
\hline Male & 40 & 66.7 & 18 & 72.0 & 22 & 62.9 & \\
\hline Female & 20 & 33.3 & 7 & 28.0 & 13 & 37.1 & 0.581 \\
\hline Age (mean $\pm S D)$ & $68.7 \pm 10.7$ & & $67.8 \pm 10.4$ & & $69.3 \pm 11.1$ & & 0.587 \\
\hline \multicolumn{8}{|l|}{ Race/ethnicity } \\
\hline White, non-Hispanic & 53 & 88.3 & 22 & 88.0 & 31 & 88.6 & \\
\hline Non-white & 7 & 11.7 & 3 & 12.0 & 4 & 11.4 & 0.642 \\
\hline \multicolumn{8}{|l|}{ Annual household income } \\
\hline$<\$ 20,000$ & 10 & 17.0 & 4 & 16.0 & 6 & 17.1 & \\
\hline$\$ 20,000-\$ 39,999$ & 14 & 23.7 & 5 & 20.0 & 9 & 25.7 & \\
\hline$\$ 40,000-\$ 59,999$ & 12 & 20.3 & 5 & 20.0 & 7 & 20.0 & \\
\hline$>\$ 60,000$ & 23 & 39.0 & 11 & 44.0 & 12 & 34.3 & 0.919 \\
\hline \multicolumn{8}{|l|}{ Medical history } \\
\hline History of cardiovascular disease & 30 & 50.0 & 11 & 44.0 & 19 & 54.3 & 0.601 \\
\hline History of stroke & 10 & 16.7 & 5 & 20.0 & 5 & 14.3 & 0.728 \\
\hline $\begin{array}{l}\text { Emphysema and/or chronic } \\
\text { obstructive pulmonary disease }\end{array}$ & 12 & 20.0 & 5 & 20.0 & 7 & 20.0 & 1.000 \\
\hline Cancer & 14 & 23.3 & 4 & 16.0 & 10 & 28.6 & 0.357 \\
\hline \multicolumn{8}{|l|}{ Atherosclerosis risk factors } \\
\hline Current smoker & 12 & 20.0 & 6 & 24.0 & 6 & I7.I & 0.337 \\
\hline Former smoker & 38 & 63.3 & 17 & 68.0 & 21 & 60.0 & \\
\hline Never smoker & 10 & 16.7 & 2 & 8.0 & 8 & 22.9 & \\
\hline Type 2 diabetes & 21 & 35.0 & 8 & 32.0 & 13 & 37.1 & 0.787 \\
\hline Hypertension & 45 & 75.0 & 22 & 88.0 & 23 & 65.7 & 0.071 \\
\hline Obesity diagnosis & 10 & 16.7 & 4 & 16.0 & 6 & 17.1 & 1.000 \\
\hline \multicolumn{8}{|l|}{ Body mass index } \\
\hline Mean \pm SD & $28.8 \pm 5.6$ & & $28.7 \pm 5.2$ & & $28.9 \pm 6.0$ & & 0.924 \\
\hline Underweight $(<18.5)$ & 0 & 0.0 & 0 & 0.0 & 0 & 0.0 & \\
\hline Normal (I8.5-24.99) & 16 & 26.7 & 6 & 24.0 & 10 & 28.6 & \\
\hline Overweight (25.0-29.99) & 20 & 33.3 & 8 & 40.0 & 12 & 34.3 & \\
\hline Obese class I (30.0-34.99) & 19 & 31.7 & 10 & 32.0 & 9 & 25.7 & \\
\hline Obese class II (35.0-39.99) & 2 & 3.3 & 0 & 0.0 & 2 & 5.7 & \\
\hline
\end{tabular}

Note: Participants with a history of I+ endovascular or operative procedures were categorized as RV versus participants with NV.

Abbreviations: PAD, peripheral arterial disease; RV, revascularized; NV, native vasculature.

and nutrition or body composition, ${ }^{12}$ and data obtained from such a specific population may also limit the generalizability of research findings. Even so, studies of recruitment methods and demographic influences on study participation have offered possible explanations for the challenges faced in this study.

\section{Physical limitations and functional decline}

Patients were excluded from the PAD study primarily for having a history of revascularization (if recruited after the 6-month midpoint of the study) or for being unable to confirm their PAD diagnoses. Among the unconfirmable cases, two categorically denied having a PAD diagnosis, whereas the remaining patients stated that they "likely" or "probably" had been diagnosed with PAD but were struggling at the time with other chronic illnesses. These patients could not recall if their clinicians had mentioned PAD to them when discussing their various treatments, but when asked to elaborate further, reported having PAD-like symptoms (intermittent claudication or critical limb ischemia). This observation has been reported in other papers, where a high prevalence of comorbid conditions coupled with patients' lack of familiarity with PAD result in a more limited pool of eligible subjects. ${ }^{8,15}$ More recently, an evaluation of strategies for recruiting Latino PAD patients for an exercise intervention encountered similar difficulties. ${ }^{16}$ Throughout our recruitment efforts, potential participants reported a variety of comorbidities that influenced their decision whether to participate. Patients expressed that diminished physical function due to CVD, diabetic neuropathy, emphysema, chronic obstructive pulmonary disease, and after-effects of strokes and related surgeries contributed to a disease burden that made the daily business of living difficult, including those patients who consented to participation.

\section{Transportation}

The second key reason for nonparticipation related to transportation. Patients who declined to participate for this reason 
stated that they 1) physically felt unable to drive and did not have a friend or relative to drive them, 2) considered themselves able drivers but felt anxious about navigating an urban area, 3) said that they were able drivers, but deemed making the trip to participate in a study to be too burdensome. While there is a wide-ranging network of public transportation in the Minneapolis/Saint Paul metro area, very few potential subjects were willing to consider utilizing this option.

\section{Age}

It is difficult to discern to what extent transportation was an obstacle due to patients' disease burden or because of other factors and an important alternate factor is likely age. PAD and other vascular diseases tend to affect people aged 50 and older, but many patients are over the age of 65 . As a result, the declining physical mobility and cognitive function that are characteristic of aging may have a substantial impact on patients' receptiveness to recruitment. Older adults comprise a uniquely challenging population in study recruitment and are therefore significantly underrepresented in clinical research. ${ }^{17,18} \mathrm{~A}$ whole range of factors shapes this dynamic, but most common among them are the aforementioned issue of transportation as well as the difficulty of identifying and contacting potential subjects who are functionally limited and/or homebound. Moreover, a general mistrust of interacting with strangers or medical professionals is a recurring observation. Older patients often approach people unknown to them with suspicion and frequently feel wary of sharing personal information with researchers. ${ }^{19}$ Lastly, older patients regularly express a misperception regarding the purpose of research studies and may confusedly view participation as an optional or unnecessary component of clinical treatment. ${ }^{20}$ It is possible that a combination of these reasons prevented the majority of identified PAD patients (93.2\%) from considering participation in this study. There is an overall consensus that the existing body of literature has provided scant or incomplete descriptions of techniques used for recruiting older participants, ${ }^{21}$ further limiting the ability to identify the methods that may be most efficacious. Nevertheless, there are approaches that future researchers may use to improve recruitment. Identifying and contacting older subjects in statistically significant numbers requires an especially large input of resources, manpower, and time. Enlisting the assistance of physicians who directly interact with patients can be an important source of participants. In this study, $2.2 \%$ of the 1,374 patients identified via billing records participated in data collection, whereas $22.3 \%$ of the 72 patients referred directly by clinicians consented to participation. The latter group ultimately comprised $68 \%$ of the total participant cohort, suggesting that recruiting PAD patients at the point of clinical contact may be more effective than mass-mailing.

Even so, physicians contend with a heavy workload and may not be willing or able to use time with patients to relay information about a research study, particularly when they feel they have no personal incentive to do so. ${ }^{22}$ Consideration should be given to establishing a mutually beneficial partnership with health care providers and organizations - one that encourages clinicians to incorporate study recruitment into daily interaction with patients, while researchers share findings in an immediately translatable and clinically relevant manner. Such an approach may be more effective than mail-outs to patients identified via hospital billing records - a method that ultimately did not produce a high yield of recruits in this study.

During the planning stage, recruitment of older subjects should also incorporate input from the target population itself. Focus groups and clinic-based interviews of older patients can delineate what methods and inducements may be most likely to attract potential subjects and create a greater sense of researcher-subject cooperation in the process. ${ }^{23}$ Piloting the recruitment strategy with a small representative sample can then help refine the study plan further and clarify issues with written materials, consent forms, and so forth that may be burdensome or convoluted for older patients..$^{18}$ Finally, consideration should also be given to structuring studies so that recruitment and data collection take place in the same location, preferably the same locations where patients receive regular care, thereby mitigating difficulties with transportation.

\section{Racial and ethnic minorities}

The racial/ethnic makeup of the target population may be a less apparent, but possibly significant reason for our difficulty recruiting PAD patients. Minorities in general and African Americans in particular carry a disproportionately higher burden of both PAD and CVD, with greater rates of limb amputation and vascular-related mortality than their Caucasian counterparts. ${ }^{24}$ This study recruited subjects from a racially diverse region - over $17 \%$ of the metro-area population belong to a minority race or ethnicity, primarily Latinos and African Americans. Nonetheless, out of 60 participants none were Latino, and six identified as black/African American. While this constitutes $10 \%$ of the cohort, oversampling African Americans was an important study goal that remained unmet. 
There is a variety of explanations for this outcome. Both public health and clinical care institutions are generally unaware of the importance of screening for PAD and its highly prevalent risk factors. ${ }^{6}$ For minority groups like African Americans, however, this phenomenon is more exacerbated. Evaluations of racial disparities in research have observed that African Americans with PAD make use of medical care less frequently than Caucasians, and if diagnosed, tend to receive less comprehensive treatment. ${ }^{25}$ Parsing the causes, socioeconomic and otherwise, of systemic racial/ethnic disparities in medical treatment is beyond the scope of this article. Nonetheless, the recurring issue of mistrust may be especially pertinent to recruiting minorities for a PAD study. Past abuses of research subjects and culturally imbedded mistrust of physicians might disincline African Americans and other minorities from participating in clinical research. ${ }^{26}$ Older minorities are also markedly wary of interacting with researchers, ${ }^{27}$ and mistrust arising from both advanced age and race/ethnicity might has discouraged the PAD patients contacted for this study from being receptive to recruitment.

Even so, there is evidence to suggest that this population's distrust of clinicians and researchers could be effectively mitigated in future studies. Communication is a primary concern; studies have reported that minorities feel physicians are frequently vague in their communication to patients and provide insufficient information about their illnesses and treatments. ${ }^{28}$ When asked to participate in studies, minorities have stated that they are inclined to think researchers will intentionally withhold important details of study involvement and even subject participants to unnecessary risks. ${ }^{29}$ The process of informed consent may be perceived as confusing and misleading as well. In order to address these concerns, more recent studies have attempted other methods with measurable success. Clinical studies of African Americans and Latinos reported that community-based participatory research, ${ }^{30}$ in which community representatives are involved in study design, recruitment, and implementation, have yielded significant rates of recruitment and participation..$^{31}$ As a nontraditional approach, community-based participatory research bypasses institution-based research and brings data collection efforts to subjects' home areas. In doing so, transportation difficulties are also largely avoided. Furthermore, participants have reported feeling personally invested in the success of such studies ${ }^{32}$ and have helped to modify study materials so that they are culturally tailored to the target population. ${ }^{33}$ A community-based participatory research-like approach may be effective in PAD research, regardless of patients' racial/ethnic background and should be considered as a viable option in future studies.

\section{Mental health}

Finally, mental health might also have been a significant mediator of recruitment for this study. There is considerable evidence that mood disorders, particularly depression, are significantly associated with CVD. Prevalence studies have observed that having depressive symptoms is an independent risk factor for CVD and CVD events. ${ }^{34}$ The Nurses' Health Study reported that depression was a significant risk factor for CVD-related mortality in women, ${ }^{35}$ and an assessment of Australian patients found that self-reported mental health was a greater predictor of CVD outcomes than self-reported physical health. ${ }^{36}$ In 1,024 CVD patients, a significant positive association between depressive symptoms and both prevalent PAD and ensuing PAD events was observed. ${ }^{37}$ The case-control assessment of 131 PAD patients by Remes et al similarly reported significantly worse scores on depressive symptom surveys compared to matched healthy controls. ${ }^{38}$ Studies of PAD patients' physical function also mirror these findings; depressive symptoms are associated with greater pain and decreased maximum walking ability, ${ }^{39}$ as well as a faster rate of functional decline in depressive versus nondepressed patients. ${ }^{40}$ Lastly, investigators reported that depressive patients who have undergone revascularization treatment consistently report worse postprocedural symptoms ${ }^{41}$ and experience a higher incidence of CVD events and mortality than nondepressives. ${ }^{42}$

Beyond the worsened mood states that can accompany physical decline in people with $\mathrm{PAD}$, there is much that is still unknown about the role of mental health in treating the disease, and to date, there have been no studies of mental health in PAD recruitment. Whereas the American Heart Association recommends screening for depression in all vascular patients, this guideline is frequently disregarded and mood disorders largely remain untreated. ${ }^{34}$ Such a dynamic need not continue, however, and consideration should be given in future PAD studies to screen potential subjects for depression, regardless of whether they have a previously established clinical diagnosis. If as a result it becomes evident that depressive patients largely decline study participation, such an observation should form the basis for revising recruitment approaches, for example, by collaborating with mental health clinicians and social workers who specialize in elderly populations and who are trained to provide mental health care.

Recently, a small intervention trial found that after 2 months of home-based, self-administered mood therapy education, 13 PAD patients experienced a significant improvement in depressive symptoms and overall mental 
health. ${ }^{43}$ Such a finding is preliminary and must be replicated with larger cohorts. Nevertheless, it offers the possibility that addressing mental health issues in a nonclinical setting may be beneficial both to patients and for recruitment efforts. Assessments of the homebound elderly additionally concluded that this population (which is more likely to suffer from depression than able-bodied counterparts) experiences very limited improvement in mood using pharmacological treatment, ${ }^{44}$ which further supports the use of alternative methodologies.

\section{Conclusion}

This article evaluated the feasibility of recruiting vascular patients for a study of nutritional status, body composition, and PAD severity. Primary obstacles to recruiting a significant number of participants included patients feeling burdened by their symptoms and coexistent chronic illnesses and difficulties with using or obtaining transportation. The inherent lack of availability of demographic information in purposive sampling precluded identifying more generalizable reasons for nonparticipation. Furthermore, as a cross-sectional viability investigation, this study had relatively limited resources and was unable to employ multisite recruitment. Nevertheless, data collection was completed and results of patients' assessments are presented elsewhere. Challenges in recruiting and retaining subjects should be addressed in future studies, and there is a body of evidence that offers potentially useful strategies. Consideration should be given to communityand home-based recruitment, particularly in cooperation with community representatives. Special emphasis should be placed on collecting stakeholders' feedback on how best to approach potential participants and how to tailor study materials to maximize clarity and ease of use. Whenever possible, data collection must take place either in subjects' home environments or in the clinical settings where they already receive regular care. Such an approach can alleviate difficulties with transportation and help build a more fruitful partnership with clinical organizations. Moreover, if recruitment takes place in health care settings that predominantly serve racial and ethnic minorities, this will allow for data collection from a more diverse cohort. Finally, in order to address the significant issue of depressive mood disorders in patients, PAD researchers should give strong consideration to partnering with mental health care providers and specialized social workers. While these strategies will still limit recruitment to the symptomatic, diagnosed subpopulation PAD patients, they will contribute to a more efficient and effective methodology.

\section{Funding}

The authors received no financial support for the research, authorship, and/or publication of this article.

\section{Disclosure}

The authors declare no potential conflicts of interest with respect to the research, authorship, and/or publication of this article.

\section{References}

1. Hirsch AT, Haskal ZJ, Hertzer NR, et al. ACC/AHA 2005 Practice Guidelines for the management of patients with peripheral arterial disease (lower extremity, renal, mesenteric, and abdominal aortic): a collaborative report from the American Association for Vascular Surgery/ Society for Vascular Surgery, Society for Cardiovascular Angiography and Interventions, Society for Vascular Medicine and Biology, Society of Interventional Radiology, and the ACC/AHA Task Force on Practice Guidelines (Writing Committee to Develop Guidelines for the Management of Patients With Peripheral Arterial Disease): endorsed by the American Association of Cardiovascular and Pulmonary Rehabilitation; National Heart, Lung, and Blood Institute; Society for Vascular Nursing; TransAtlantic Inter-Society Consensus; and Vascular Disease Foundation. Circulation. 2006;113(11):e463-e654.

2. Rooke TW, Hirsch AT, Misra S, et al. 2011 ACCF/AHA focused update of the guideline for the management of patients with peripheral artery disease (updating the 2005 guideline). Vasc Med. 2011;16(6): 452-476.

3. Norgren L, Hiatt WR, Dormandy JA, et al. The next 10 years in the management of peripheral artery disease: perspectives from the "PAD 2009” Conference. Eur J Vasc Endovasc Surg. 2010;40(3):375-380.

4. Lloyd-Jones D, Adams RJ, Brown TM, et al. Executive summary: heart disease and stroke statistics-2010 update: a report from the American Heart Association. Circulation. 2010;121(7):948-954.

5. Rice TW, Lumsden AB. Optimal medical management of peripheral arterial disease. Vasc Endovascular Surg. 2006;40(4):312-327.

6. Hirsch AT, Criqui MH, Treat-Jacobson D, et al. Peripheral arterial disease detection, awareness, and treatment in primary care. JAMA. 2001; 286(11):1317-1324.

7. Mahoney EM, Wang K, Cohen DJ, et al. One-year costs in patients with a history of or at risk for atherothrombosis in the United States. Circ Cardiovasc Qual Outcomes. 2008;1(1):38-45.

8. Norgren L, Hiatt WR, Dormandy JA, Nehler MR, Harris KA, Fowkes FG. Inter-Society consensus for the management of peripheral arterial disease (TASC II). J Vasc Surg. 2007;45(S1):S5-S67.

9. Stoner MC, Defreitas DJ, Manwaring MM, Carter JJ, Parker FM, Powell CS. Cost per day of patency: understanding the impact of patency and reintervention in a sustainable model of healthcare. $J$ Vasc Surg. 2008;48(6):1489-1496.

10. Flu H, van der Hage JH, Knippenberg B, Merkus JW, Hamming JF, Lardenoye JW. Treatment for peripheral arterial obstructive disease: an appraisal of the economic outcome of complications. J Vasc Surg. 2008; 48(2):368e-376e.

11. Parmenter BJ, Raymond J, Dinnen P, Singh MA. A systematic review of randomized controlled trials: walking versus alternative exercise prescription as treatment for intermittent claudication. Atherosclerosis. 2011;218(1):1-12.

12. Brostow DP, Hirsch AT, Collins TC, Kurzer MS. The role of nutrition and body composition in peripheral arterial disease. Nat Rev Cardiol. 2012;9(11):634-643.

13. Schiano V, Laurenzano E, Brevetti G, et al. Omega-3 polyunsaturated fatty acid in peripheral arterial disease: effect on lipid pattern, disease severity, inflammation profile, and endothelial function. Clin Nutr. 2008; 27(2):241-247. 
14. De Jong SC, Stehouwer CD, van den Berg M, Geurts TW, Bouter LM, Rauwerda JA. Normohomocysteinaemia and vitamin-treated hyperhomocysteinaemia are associated with similar risks of cardiovascular events in patients with premature peripheral arterial occlusive disease. A prospective cohort study. J Intern Med. 1999;246(3):87-96.

15. Hirsch AT, Murphy TP, Lovell MB, et al. Gaps in public knowledge of peripheral arterial disease: the first national PAD public awareness survey. Circulation. 2007;116(18):2086-2094.

16. Guidon M, McGee H. Recruitment to clinical trials of exercise: challenges in the peripheral arterial disease population. Physiotherapy. 2013;99(4):305-310.

17. Carroll CB, Zajicek JP. Designing clinical trials in older people. Maturitas. 2011;68(4):337-341.

18. McMurdo ME, Roberts $\mathrm{H}$, Parker S, et al. Improving recruitment of older people to research through good practice. Age Ageing. 2011; 40(6):659-665.

19. Ritchie CS, Dennis CS. Research challenges to recruitment and retention in a study of homebound older adults: lessons learned from the nutritional and dental screening program. Care Manag J. 1999;1(1):55-61.

20. Ridda I, MacIntyre CR, Lindley RI, Tan TC. Difficulties in recruiting older people in clinical trials: an examination of barriers and solutions. Vaccine. 2010;28(4):901-906.

21. Ndumele CD, Ableman G, Russell BE, Gurrola E, Hicks LS. Publication of recruitment methods in focus group research of minority populations with chronic disease: a systematic review. $J$ Health Care Poor Underserved. 2011;22(1):5-23.

22. Costescu DJ, Cullimore AJ. Lessons learned from a resident-led clinical trial in obstetrics. Clin Trials. 2013;10(4):612-616.

23. Foster CE, Brennan G, Matthews A, McAdam C, Fitzsimons C, Mutrie N. Recruiting participants to walking intervention studies: a systematic review. Int J Behav Nutr Phys Act. 2011;8:137.

24. Allison MA, Peralta CA, Wassel CL, et al. Genetic ancestry and lower extremity peripheral artery disease in the multi-ethnic study of atherosclerosis. Vasc Med. 2010;15(5):351-359.

25. Amaranto DJ, Abbas F, Krantz S, Pearce WH, Wang E, Kibbe MR. An evaluation of gender and racial disparity in the decision to treat surgically arterial disease. J Vasc Surg. 2009;50(6):1340-1347.

26. O’Brien RL, Kosoko-Lasaki O, Cook CT, Kissell J, Peak F, Williams EH. Self-assessment of cultural attitudes and competence of clinical investigators to enhance recruitment and participation of minority populations in research. $J$ Natl Med Assoc. 2006;98(5):674-682.

27. Choi NG, Smith J. Reaching out to racial/ethnic minority older persons for elderly nutrition programs. J Nutr Elder. 2004;24(1):89-104.

28. Ashton CM, Haidet P, Paterniti DA, et al. Racial and ethnic disparities in the use of health services: bias, preferences, or poor communication? J Gen Intern Med. 2003;18(2):146-152.

29. Corbie-Smith G, Thomas SB, St George DM. Distrust, race, and research. Arch Intern Med. 2002;162(21):2458-2463.

30. Israel BA, Schulz AJ, Parker EA, Becker AB. Review of communitybased research: assessing partnership approaches to improve public health. Апnи Rev Public Health. 1998;19:173-202.

31. Woods G, Levinson AH, Jones $\mathrm{G}$, et al. The living well by faith health and wellness program for African Americans: an exemplar of communitybased participatory research. Ethn Dis. 2013;23(2):223-229.
32. DeHaven MJ, Ramos-Roman MA, Gimpel N, et al. The GoodNEWS (genes, nutrition, exercise, wellness, and spiritual growth) Trial: a community-based participatory research (CBPR) trial with AfricanAmerican church congregations for reducing cardiovascular disease risk factors-recruitment, measurement, and randomization. Contemp Clin Trials. 2011;32(5):630-640.

33. Henderson VA, Barr KL, An LC, et al. Community-based participatory research and user-centered design in a diabetes medication information and decision tool. Prog Community Health Partnersh. 2013;7(2): 171-184.

34. Huffman JC, Celano CM, Beach SR, Motiwala SR, Januzzi JL. Depression and cardiac disease: epidemiology, mechanisms, and diagnosis. Cardiovasc Psychiatry Neurol. 2013;2013:695925.

35. Pan A, Lucas M, Sun Q, et al. Increased mortality risk in women with depression and diabetes mellitus. Arch Gen Psychiatry. 2011;68(1): $42-50$.

36. O’Neil A, Williams ED, Stevenson CE, Oldenburg B, Berk M, Sanderson K. Co-morbid cardiovascular disease and depression: sequence of disease onset is linked to mental but not physical self-rated health. Results from a cross-sectional, population-based study. Soc Psychiatry Psychiatr Epidemiol. 2012;47(7):1145-1151.

37. Grenon SM, Hiramoto J, Smolderen KG, Vittinghoff E, Whooley MA, Cohen BE. Association between depression and peripheral artery disease: insights from the heart and soul study. $J$ Am Heart Assoc. 2012;1(4): $\mathrm{e} 002667$.

38. Remes L, Isoaho R, Vahlberg T, Viitanen M, Rautava P. Quality of life among lower extremity peripheral arterial disease patients who have undergone endovascular or surgical revascularization: a case-control study. Eur J Vasc Endovasc Surg. 2010;40(5):618-625.

39. Smolderen KG, Aquarius AE, de Vries J, Smith OR, Hamming JF, Denollet J. Depressive symptoms in peripheral arterial disease: a follow-up study on prevalence, stability, and risk factors. J Affect Disord. 2008;110(1-2):27-35.

40. Ruo B, Liu K, Tian L, et al. Persistent depressive symptoms and functional decline among patients with peripheral arterial disease. Psychosom Med. 2007;69(5):415-424.

41. Smolderen KG, Safley DM, House JA, Spertus JA, Marso SP. Percutaneous transluminal angioplasty: association between depressive symptoms and diminished health status benefits. Vasc Med. 2011;16(4): 260-266.

42. Cherr GS, Zimmerman PM, Wang J, Dosluoglu HH. Patients with depression are at increased risk for secondary cardiovascular events after lower extremity revascularization. J Gen Intern Med. 2008;23(5): 629-634.

43. Garnefski N, Kraaij V, Wijers E, Hamming J. Effects of a cognitivebehavioral self-help program on depressed mood for people with peripheral arterial disease. J Clin Psychol Med Settings. 2013;20(2): 186-191.

44. Choi NG, Sirey JA, Bruce ML. Depression in homebound older adults: recent advances in screening and psychosocial interventions. Curr Transl Geriatr Exp Gerontol Rep. 2013;2(1):16-23.
Patient Preference and Adherence

\section{Publish your work in this journal}

Patient Preference and Adherence is an international, peer-reviewed, open access journal that focuses on the growing importance of patient preference and adherence throughout the therapeutic continuum. Patient satisfaction, acceptability, quality of life, compliance, persistence and their role in developing new therapeutic modalities and compounds to optimize

\section{Dovepress}

clinical outcomes for existing disease states are major areas of interest for the journal. This journal has been accepted for indexing on PubMed Central. The manuscript management system is completely online and includes a very quick and fair peer-review system, which is all easy to use. Visit http://www dovepress.com/testimonials.php to read real quotes from published authors. 